\title{
TOWARDS A SUBSTANTIVE THEORY OF SYNERGY
}

\author{
GERHARD BENECKE \\ WILLEM SCHURINK \\ GERT ROODT \\ groodt@uj.ac.za \\ Department of Human Resource Management \\ University of Johannesburg
}

\begin{abstract}
The literature on synergy suggests that synergy is systemic and hence should be viewed in the context of processes, but that an integrative definition of this phenomenon does not exist. Against this background the article explains synergy as a concept describing the systemic processes whereby business units of diversified organisations may generate greater value through working as one system rather than working as separate entities. Through the application of grounded theory in a modernistic qualitative context and the use of a case study a substantive theory is presented for leading change towards synergy in a diversified organisation that has business units in three continents.
\end{abstract}

Key words: Synergy, competitive performance, diversification, co-ordination

In the mergers and acquisitions literature, synergy usually refers to financial synergy that is gained through the merging of conglomerates (Chang, 1990), while in the industrial economics literature, synergy features in the context of economies of scale that lead to cost savings (Chang, 1990).

Harwood (2000, pp. 523-529) quotes Castell, Gregory, Hindle, James and Ragsdall who write that "synergy comes from the Greek word synergos which means working together. This demands a platform for participation through the development of dialogues, between disciplines and people, the very stuff of systems thinking." Naudé, Heyns, Bester, Puig and Tucker (2002, p. 2) define synergy as the ability of two or more business units or companies to generate greater value working together than they would working apart, while Juga (1996, p. 51 ) identifies synergism as the co-operative action of discrete agencies in such a way that the total effect is greater than the sum of the effects taken independently. Itamic and Roehl (Juga, 1996) are of the opinion that synergy results from the process of making better use of resources, including physical assets such as manufacturing facilities, and invisible property such as brand name, customer knowledge, technological expertise and corporate culture. When the organisation exploits its unique resources it achieves synergy. Itamic and Roehl (in Juga, 1996, p. 52) go on to argue that synergy is a "free ride", because the invisible assets developed in one part of the company can be used elsewhere without being depleted. Steinfield, De Wit, Adelaar, Bruins, Fielt, Hoefsloot, Smit and Bouwman (2001, pp. 203-213) delineate a synergy strategy as one where an organisation explicitly links its virtual and physical presence, exploiting each channel's strengths.

Synergy is defined by Gupta and Roos (2001, p. 298) as the interaction of two or more intellectual capital resources from previously sovereign organisations, which enhances the combined effect of value creation and competitive performance, which effect is greater than the sum of the individual effects. Argenti (in Krumm, Dewulf \& De Jonge, 1998, p. 374) defines synergy as "the concept that the combination of two or more different businesses, activities, or processes will create an overall value that is greater than the sum of the individual parts".

The synergy concept suggests that advantages are created when economies of scale and speed are combined with administrative co-ordination (Krumm et al., 1998). Cockerill (1995) points out that Aristotle in ancient Greece was probably one of the first to propose a systems idea when he noticed that some wholes exhibit properties that were not noted in the individual parts of the entity. More recently, in the 1930s, Gestalt psychologists observed that "the whole is more than the sum of its parts". Today's systemic equivalent is called "synergy" (Cockerill, 1995, pp. 4-8)
Harris (2004) contends that synergy represents a dynamic process, involves adaptation and learning, creates an integrated solution, entails joint action by many in which the total effect is greater than the sum of the effects when acting independently, does not signify compromise, and facilitates the release of team energies.

Describing synergy as increased efficiency in the sharing of skills and other assets, Ansoff (in Ensign, 1998) identifies four types of synergy, namely sales, operating, investment and management synergy. Wells (in Chang, 1990), in turn, identifies five categories of synergy in diversified organisations, namely financial synergy, which comes from risk reduction; entrepreneurial synergy, which flows from the pursuit of attractive new investment opportunities; expansion synergy, which originates from the application of existing resources to new business; market power synergy, which arises from cross-subsidisation; and operational synergy, which comes from sharing activities and knowledge.

If the preceding definitions and their operationalisation are scrutinised, it is clear that there does not exist a coherent theory of how to lead a change process towards achieving synergy in a global and diversified organisation.

From the preceding discussion the most striking features of synergy appear to be the following:

- It is systemic and hence should be viewed in the context of processes.

- It is based on the Gestalt theory proposed by Max Wertheimer (1880-1943), Wolfgang Köhler (1887-1967) and Kurt Kofka (1886-1941) who believed that "the whole is more than the sum of its parts" (Hergenhahn, 1976, p. 237).

- It implies in the business context that business units working together will generate greater value than they would by working apart.

- It is the result of a process whereby better use of physical and invisible resources is made by viewing the total diversified organisation as one system.

- It is exploitive and provides a cheaper alternative, because invisible assets like brand name, customer knowledge, technological expertise and corporate culture can be used elsewhere in the organisation without the risk of being depleted.

Drawn from the above summary we propose the following integrative definition of synergy: Synergy is a concept that describes the systemic processes whereby business units of diverse, complex organisations will generate greater value through working as one system than working as separate entities.

In the 1960s and the 1970s companies were looking for innovative ways to achieve growth (Ensign, 1998). Synergy was used as one of 
the key components of various strategy formulation frameworks and was especially used for motivating corporate growth through diversification (Juga, 1996). Diversification was seen as a way of ensuring profitability (Ensign, 1998). This explains why most synergy research has been focusing on diversification (Ensign, 1998). Chang (1990) studied the empirical relationship between synergy and diversification and confirms that synergy is achieved by sharing resources among the business units of a diversified firm. According to him, the existence of synergy can be explained in terms of the relatedness between an organisation's business units, the particular strengths of the diversified organisation, and the organisation's structure.

Naudé et al. (2002) point out that most major diversified companies have decentralised into business units with profit responsibility embracing autonomy and practising decentralisation with near religious devotion. They (Naudé et al., 2002) are of the opinion that uncontrolled decentralisation undermines the pursuit of interrelationships between business units and regard the organisational difficulties of achieving clearly beneficial interrelationships as the main reason why many managers reject synergy.

Having studied the relationship between diversification and the degree of synergy between business units on the economic performance of an organisation, Rumelt (in Ensign, 1998) identifies three types of synergy, namely operating, managerial and financial synergy. A large number of studies on the diversified organisation are based on Rumelt's ideas (in Ensign, 1998). However, these studies generally do not test whether synergy is actually achieved, since they assume synergy when there is relatedness between the business units (Ensign, 1998). Synergy studies basically focus on the type of diversification and the impact it has on the competitive advantage of the organisation (Ensign, 1998).

The need to maintain a competitive advantage is an important driving force in diversified organisations (Ensign, 1998). Krumm et al. (1998) argue that corporations have to understand and appreciate their own capabilities and resources in order to establish a sustainable competitive advantage in the marketplace. Porter (in Ensign, 1998) suggests that a way to achieve such an advantage is to develop interrelationships between business units that will lead to effective resource sharing and synergy in executing value-chain activities. Rowley (2002) argues that the value chain features in areas where a company has the potential to gain a competitive advantage in the marketplace. To gain such an advantage, a business needs to perform some function in the value chain better than its competitors. This can be achieved through alliances with partnering companies and the resultant synergy (Rowley, 2002).

Co-ordination tends to become increasingly more important as the business environment becomes more competitive (Ensign, 1998). Chang (1990) points out that the stronger the competitive advantage of constituent business units the more difficult it becomes to realise a diversified company's synergy.) Shaver (2006) warns that the merging of businesses may adversely affect their competitive advantage in that the facilitation of synergy may amplify threats and inhibit the ability to react positively to favourable conditions in the business environment.

Rowley (2002) identifies supply, production, marketing, delivery and support as the primary steps in the value chain. Ensign (1998) points out that much research has focused on the extent to which business units of a diversified company are related or unrelated to each other. He argues that the development of successful interrelationships in diversified companies depends on the relatedness between specific activities rather than between entire business units. Ensign (1998) recommends that studies of interrelationships must focus on the relatedness of valuechain activities in different business units. In Ensign's (1998) view, relatedness of activities where potential interrelationships can be developed must be further explored, since it may help determining a diversified organisation's synergy potential. Franzsen, Van der Merwe, Buys, Bischoff, Courtney, Varachia, Cox and Miller (2001) describe a value chain as a graphic presentation of the activities of a business, which activities may be divided into primary and secondary activities. Primary activities are the activities involved in the physical creation, sale and transfer of a product or service, while secondary activities entail procurement, technology development, human resource management, financial activities and quality management (Franzsen et al., 2001).

Naudé et al. (2002) argue that the ability to share activities in the value chain is a strong basis for corporate synergy, because sharing often enhances a competitive advantage by lowering costs or encouraging differentiation. However, they (Naudé et al., 2002) warn that not all sharing will lead to a competitive advantage and that a diversified organisation may encounter deep organisational resistance, even to beneficial sharing possibilities. According to them (Naudé et al., 2002), these realities have led to the rejection of synergy by many companies and a retreat to the false simplicity of portfolio management.

Since the middle 1980s, interest in the analysis of competitive advantage shifted towards internal organisational aspects (Krumm et al., 1998). Competitive advantage was perceived by diversified organisations as depending less on corporate decisions regarding marketing and more on sharing internal resources (Krumm et al., 1998). Naudé et al. (2002) point out that resource sharing can lower costs if it achieves economies of scale, boosts utilisation efficiency or encourages information sharing. Argenti (1994) argues that synergy is primarily achieved through resource sharing by combining two or more activities, processes or businesses to create greater value than they would be able to create independently. The popularity of the resource-based approach has to a large degree been created by Prahalad and Hamel's core-competence thinking (Krumm et al., 1998).

From the literature it is clear that only a few synergy studies have thus far investigated resource sharing and profitability (Ensign, 1998). Chang's (1990) study found that synergy is a function of competitive advantage derived from shared resources. Gupta and Govindarajan (in Ensign, 1998) examined resource sharing but unfortunately derived only one hypothesis on resource sharing, namely that resource sharing indeed contributes to cost effectiveness between business units (Ensign, 1998). Mahajan and Wind's findings (in Ensign, 1998) on the relationship between synergy and profitability are criticised for isolating the performance of one business unit from the performance of other units participating in resource sharing, since some business units will benefit more than others in the process (Ensign, 1998).

Waco and Wery (2004) argue that a key enabler of lasting synergies lies in approaching the diversified company in terms of the division of labour, management responsibilities and the development of common processes across business units and regions. Ensign (1998) argues that understanding interrelationships in diverse organisations is important for understanding synergy, which argument is supported by Chang's (1990) doctoral study.

Ensign (1998) classifies diversified companies into vertical, portfolio and horizontal companies.

- The vertical company is designed to transfer resources from one unit to another in a one-way or vertical fashion. Hence the vertical company may not be equipped to identify and co-ordinate the mutual sharing of resources (Ensign, 1998). Juga (1996) points out that large diversified companies can balance their dual demands for corporatelevel co-ordination and local responsiveness by establishing 
interdependent business units instead of having rigid vertical and hierarchical structures. This implies that vertical companies may have to change their interrelationships to achieve synergies (Ensign, 1998).

- Naudé et al. (2002) point out that the most often-found portfolio company is based primarily on diversification through acquisitions. The acquired business units of such a diversified company are autonomous and employees of its business units are compensated according to each one's results (Naudé et al., 2002). A company with no interrelationships between its business units is thus decentralised (Ensign, 1998). The portfolio organisation shows limited resource sharing and synergy between its business units.

- The horizontal organisation has the structure and the mechanisms to encourage the successful development of interrelationships. The characteristics of the horizontal organisation can help it to achieve a competitive advantage (Ensign, 1998). Companies have to compete effectively not only in their local context, but in wider regional and global marketplaces (Pun, 2004). They have to identify competitive priorities and implement strategies that will ensure a competitive advantage (Pun, 2004). Naudé et al. (2002) argue that a horizontal strategy that cuts across divisional boundaries should be one of the most important items on the strategic agenda of a diversified organisation. These authors (Naude et al., 2002) believe that a horizontal strategy is the mechanism by which a diversified organisation can enhance the competitive advantage of its business units. Steinfield et al. (2001) define a synergy strategy as one where a company horizontally links the strengths of different distribution channels. A horizontal strategy co-ordinates the goals and strategies of related business units, brings about interrelationships and facilitates strategy (Naudé et al., 2002). Paich (1996) warns that when systems and human resources are polarised the corporate strategy may look cohesive but in reality suffers from a lack of synergy. Ensign (1998) says that interrelationships refer to the sharing of resources and skills in activities that are related to achieving synergy, while a horizontal strategy refers to developing those interrelationships that create value towards achieving a competitive advantage.

Aligning organisational strategy to the context of the organisation is an important management task. It includes co-operation between the various business units of an organisation, more particularly co-operation that strengthens the competitive position of all business units through the sharing of capabilities such as intellectual capital. In this context synergy efforts can be seen as co-managed strategies that provide a systemic solution to the bigger organisation of which the business units are part (Ensign, 1998). When an organisation plans to acquire another company, it compares company objectives, market trends and customer input with company resources so as to identify ways to build business value. The buyer company must develop a strategic plan to identify synergies with the seller company. These synergies can later be used to identify specific key integration activities (Parenteau \& Weston, 2003).

Ensign (1998) points out that if the diversified company seeks to develop horizontal strategies that can create value for the total organisation, it must organise and manage business units in such a way that each can benefit from its link with the rest of the diversified company and that each business unit will be better off operating as part of the company than operating independently.

Upon scrutiny, the literature on synergy in organisations shows some limitations:

- No integrative theoretical framework of how to lead change towards synergy in a global and diversified organisation could be found.
- No examples of the application of grounded theory in synergy studies of global and diversified organisations could be identified.

- Only a few synergy studies investigated the issue of resource sharing and profitability (Ensign, 1998).

- No study could be found that attempted to create a systemic framework for pursuing synergies in a global and diversified organisation.

- No study of synergy could be identified that simultaneously explores all the abstract constructs of synergy, namely organisational culture, intellectual capital, strategy, organisational structure, leadership, organisational change, motivation, the balanced scorecard, value-based management, reward and communication.

In light of the preceding exposition, we decided to create a substantive integrative theoretical framework for leading change towards synergy in a global and diversified organisation by applying grounded theory in a modernist qualitative context by means of a case study.

\section{RESEARCH DESIGN}

\section{Research approach}

There is an increasing awareness particularly among qualitative researchers that one has to be clear on one's scientific values or beliefs in order to properly plan and execute a research project (see Locke, 2001; Mason, 1996; Schurink, 2004). A researcher's ontology, or her or his perceptions of the nature of social reality (or the social world) and what there is to know about it (Schurink, 2004), is a basic value of research. Denzin and Lincoln (2000) refer to ontology as the researcher's beliefs about the nature of social reality, i.e. the nature of human beings. Gill and Johnson (2002, p. 228), in turn, define ontology as the study of the essence of phenomena and the nature of their existence.

By applying a particular qualitative approach in his recent doctoral work Benecke discovered and described the meanings that the employees of a particular global and diversified company ${ }^{1}$ attached to synergy. In order to construct their social reality, including their experiences of and views on synergy, he utilised their concrete or first-order constructs as well as existing theoretical concepts, i.e. abstract symbolic tools or second-order constructs developed by scholars to illuminate human behaviour (see Mouton, 1985; Mouton \& Marais, 1990). More particularly, Benecke employed a general theoretical perspective, namely symbolic interactionism ${ }^{2}$, which has played an important role in the development of what is termed "modernist qualitative research" (Denzin \& Lincoln, 2000) ${ }^{3}$. Benecke also took note of broad assumptions arising from his personal experience of the Company and the experiences of other people closely associated with it.

The other key research value is a researcher's epistemology. This refers to where one stands in relation to the social world one studies (see Schurink, 2004). Denzin and Lincoln (2000) refer to this as the researcher's beliefs about the relationship between the inquirer and the known. Gill and Johnson (2002, p. 226) define epistemology as the branch of philosophy concerned with the study of the criteria by which we determine what does and does not constitute warranted or valid knowledge. Mason (in Schurink, 2004) views epistemology as the researcher's theory of knowledge. Clearly epistemology has to do with the principles and rules we use when we study a particular social phenomenon. Our theory of knowledge holds that knowledge can be attained by applying formalised qualitative methods and analysing data rigorously. This is in line with the so-called modernist tradition of qualitative research. 
In addition to one's ontology and epistemology it is necessary to consider one's position regarding key personal beliefs and research ethics. In contrast to their quantitative counterparts, qualitative researchers believe that they cannot be aloof from their research. They are convinced that they have to become immersed in people, social situations and any social reality they study (Schurink, 2005, e-mail communication). Assuming varying interactive social roles when observing social settings, they interview and interact with research participants so as to collect, capture and interpret data, and finally construct social worlds.

\section{Research method}

\section{Research participiants}

In accordance with purposive sampling (see Strydom \& Delport, 2002) Benecke carefully selected particular individuals and groups involved in pursuing global synergies in the Company. Then he proceeded with theoretical sampling ${ }^{4}$.

As corporate synergy falls in the domain of organisational development, which in turn can be seen as part of the responsibilities of human resource directors, Benecke identified the various Human Resource Directors of the Company's business units as critical gatekeepers. Their gatekeeping role provided insight that Benecke did not have at the outset. He approached these functionaries of the Company's South African business units and explained the purpose of the study as well as purposive and theoretical sampling and how he intended to utilise these. The Human Resource Directors approached those candidates they judged able to make a meaningful contribution and informed them that Benecke would contact them. Those participants Benecke knew personally he approached directly. The basic particulars of the in-depth interviews are presented schematically below.

\section{TABle 1:}

\section{IN-DEPTH INTERVIEWS}

\begin{tabular}{|c|c|c|c|c|c|}
\hline $\begin{array}{l}\text { Re- } \\
\text { search } \\
\text { parti- } \\
\text { cipant }\end{array}$ & $\begin{array}{l}\text { Business } \\
\text { unit }\end{array}$ & Department & Position & Date & Duration \\
\hline 1. & BWM & $\begin{array}{l}\text { Human } \\
\text { Resources }\end{array}$ & $\begin{array}{l}\text { General } \\
\text { Manager }\end{array}$ & 19.08.2004 & 95 minutes \\
\hline 2. & $\mathrm{PP}$ & $\begin{array}{l}\text { Performance } \\
\text { Improvement }\end{array}$ & $\begin{array}{l}\text { Group } \\
\text { Manager }\end{array}$ & 30.08 .2004 & 65 minutes \\
\hline 3. & PP & Marketing & $\begin{array}{l}\text { Brand } \\
\text { Investment } \\
\text { Officer }\end{array}$ & 31.08 .2004 & 42 minutes \\
\hline 4. & PP & Procurement & $\begin{array}{l}\text { Group } \\
\text { Procurement } \\
\text { Manager }\end{array}$ & 01.09 .2004 & 80 minutes \\
\hline 5. & PP & Marketing & Director & 01.09 .2004 & 75 minutes \\
\hline 6. & $\mathrm{PP}$ & Finance & Director & 03.09 .2004 & 60 minutes \\
\hline 7. & RB-T & $\begin{array}{l}\text { Executive } \\
\text { Management }\end{array}$ & $\begin{array}{l}\text { Managing } \\
\text { Director }\end{array}$ & 07.09 .2004 & 60 minutes \\
\hline 8. & RB-P & $\begin{array}{l}\text { Executive } \\
\text { Management }\end{array}$ & $\begin{array}{l}\text { General } \\
\text { Manager }\end{array}$ & 07.09.2004 & 105 minutes \\
\hline 9. & RB-S & $\begin{array}{l}\text { Executive } \\
\text { Management }\end{array}$ & Director & 08.09 .2004 & 60 minutes \\
\hline 10. & RB-S & $\begin{array}{l}\text { Information } \\
\text { Technology }\end{array}$ & IT Manager & 09.09.2004 & 60 minutes \\
\hline 11. & RB-G & $\begin{array}{l}\text { Executive } \\
\text { Management }\end{array}$ & $\begin{array}{l}\text { Managing } \\
\text { Director }\end{array}$ & 09.09.2004 & 105 minutes \\
\hline 12. & RB-T & $\begin{array}{l}\text { Project } \\
\text { Management }\end{array}$ & $\begin{array}{l}\text { Project } \\
\text { Manager }\end{array}$ & 14.09 .2004 & 45 minutes \\
\hline 13. & $\begin{array}{l}\text { Corporate } \\
\text { Office }\end{array}$ & $\begin{array}{l}\text { Employment } \\
\text { Law }\end{array}$ & Executive & 16.09 .2004 & 85 minutes \\
\hline
\end{tabular}

\begin{tabular}{|c|c|c|c|c|c|}
\hline 14. & RB-P & $\begin{array}{l}\text { Executive } \\
\text { Management }\end{array}$ & $\begin{array}{l}\text { Managing } \\
\text { Director }\end{array}$ & 16.09 .2004 & 70 minutes \\
\hline 15. & RB-S & Finance & $\begin{array}{l}\text { General } \\
\text { Manager }\end{array}$ & 16.09 .2004 & 95 minutes \\
\hline 16. & PP & $\begin{array}{l}\text { Information } \\
\text { Technology }\end{array}$ & $\begin{array}{l}\text { Chief } \\
\text { Information } \\
\text { Officer }\end{array}$ & 17.09 .2004 & 70 minutes \\
\hline 17. & $\log$ & $\begin{array}{l}\text { Executive } \\
\text { Management }\end{array}$ & Executive & 17.09 .2004 & 95 minutes \\
\hline 18. & RB-S & $\begin{array}{l}\text { Project } \\
\text { Management }\end{array}$ & $\begin{array}{l}\text { Project } \\
\text { Manager }\end{array}$ & 20.09 .2004 & 100 minutes \\
\hline 919. & Proc & $\begin{array}{l}\text { Executive } \\
\text { Management }\end{array}$ & Executive & 20.09 .2004 & 75 minutes \\
\hline 20. & BEC & $\begin{array}{l}\text { Branch } \\
\text { Management }\end{array}$ & $\begin{array}{l}\text { General } \\
\text { Manager }\end{array}$ & 21.09 .2004 & 71 minutes \\
\hline 21. & RB-S & $\begin{array}{l}\text { Organisational } \\
\text { Performance }\end{array}$ & Executive & 22.09 .2005 & 75 minutes \\
\hline 22. & $\begin{array}{l}\text { Corporate } \\
\text { Office }\end{array}$ & $\begin{array}{l}\text { Human } \\
\text { Resources }\end{array}$ & $\begin{array}{l}\text { Executive } \\
\text { Director }\end{array}$ & 01.10 .2004 & 60 minutes \\
\hline 23. & Coat & $\begin{array}{l}\text { Human } \\
\text { Resources }\end{array}$ & $\begin{array}{l}\text { Human } \\
\text { Resource } \\
\text { Director }\end{array}$ & 04.10 .2004 & 75 minutes \\
\hline 24. & $\begin{array}{l}\text { Corporate } \\
\text { Office }\end{array}$ & $\begin{array}{l}\text { Information } \\
\text { Technology }\end{array}$ & $\begin{array}{l}\text { Chief } \\
\text { Information } \\
\text { Officer }\end{array}$ & 06.10 .2004 & 60 minutes \\
\hline 25. & BWM & Marketing & $\begin{array}{l}\text { Director } \\
\text { Marketing }\end{array}$ & 07.10 .2004 & 75 minutes \\
\hline 26. & BEC & $\begin{array}{l}\text { Executive } \\
\text { Management }\end{array}$ & $\begin{array}{l}\text { Chief } \\
\text { Executive } \\
\text { officer }\end{array}$ & 21.10 .2004 & 75 minutes \\
\hline 27. & Coat & $\begin{array}{l}\text { Project } \\
\text { Management }\end{array}$ & $\begin{array}{l}\text { Projects } \\
\text { Manager }\end{array}$ & 27.10 .2004 & 120 minutes \\
\hline
\end{tabular}

Five of the operational business units, namely BWM, PP, RB, BEC and Coat, were represented in the in-depth interviews. The two business units that were not included were the overseas ones; attempts were made to conduct in-depth interviews with their visiting executives, but business pressures made it impossible.

The distribution of in-depth interviews per department was as follows: Human Resources (3), Performance Improvement (1), Marketing (3), Finance (2), Information Technology (3), Project Management (3), Employment Law (1), Branch Management (1), Organisational Performance (1), Executive Management (8) and Procurement (1).

The distribution of in-depth interviews per business unit and department is incidental, i.e. the distribution is the result of responses to my request for participation in the in-depth interviews. The strong presence of RB and PP can simply be ascribed to their respective directors' commitment to the study and the way in which they encouraged their personnel to participate.

The participants in the two focus group interviews were selected on the basis of their involvement in synergy activities in the Company. Those taking part in the first focus group interview were members of a regional synergy committee that met on 21 September 2004 in Durban ${ }^{5}$. The other focus group consisted of executives of the Company involved in an executive development programme at a local university, sponsored by the Company 6 . Schurink who attended this focus group interview explained key aspects of the study's assumptions, such as its modernist base. This raised the study's credibility in the eyes of the participants and gave them an opportunity to learn more about it and its possible applications in a business environment. 
During the focus group interviews and a video conference on the establishment of a forum for recruitment and selection in the Company Benecke acted as participant observer. The conference took place on 10 September 2004 from 15:00 to 16:00, and the seven participants were from Johannesburg (South Africa), Charlotte (North Carolina, United States) and Madrid (Spain) ${ }^{7}$.

\section{Data-gathering methods}

Creswell (1998) distinguishes four basic sources of data: observations, interviews, documents and audiovisual materials. As pointed out, in-depth as well as focus group interviews were utilised. These were supplemented with documents (minutes and reports on synergy meetings, Benecke diary and solicited essays) and participant observation. The audiovisual materials consisted of films of the focus group interviews.

\section{- Interviewing}

Basically Benecke followed Creswell's (1998) approach to interviewing: he designed protocols and used them to guide the initial and follow-up interviews. By using the interview protocol he managed to be a listener rather than a speaker during the interviews and to stay within the time limits ${ }^{8}$. The protocol also ensured consistency regarding the questions and instructions put to the participants during both the indepth and the focus group interviews. Benecke recorded the in-depth interviews with an audio cassette recorder and the focus group interviews with two audio cassette recorders (an extra measure to ensure that all the participants would be audible on the recordings) and a video camera. The choice of location for the interviews was left to the participants so as to ensure that they would feel secure and at ease. All participants were provided with an informed consent form for signing at the conclusion of the individual in-depth as well as the focus group interviews.

For member validation Benecke selected participants 26 and 27 to comment on my construction of the participants' social worlds ${ }^{9}$. For this purpose he used an interview protocol derived from his construction of the social reality of synergy in the company.

- Documents

The documents that were used included the minutes of synergy or shared services committees and forums of the Company. Nine requested essays as follow-ups to the initial in-depth interviews were also used. The essays were requested per e-mail from 25 participants ${ }^{10}$. Benecke's diary consisted mainly of electronic communication between his study leaders and himself; the e-mail messages were used to compile the auto ethnography.

\section{- Participant observation}

Following Creswell's (1998) steps for observation (not to be confused with his steps for interviewing), Benecke developed what may be referred to as a "field notes protocol". This protocol was completed for both the focus group interviews and the video conference. In the protocol provision was made for: (1) descriptive (observational) notes, (2) reflective notes, (3) reflections on analysis and evolving constructs, (4) reflections on method, (5) reflections on ethical dilemmas and concerns, and (6) reflections on my frame of mind.

- Audiovisual materials

With the exception of the cassette and video recordings of the interviews, no other audiovisual materials were utilised. This was in line with the original decision that the use of this source of data would be too demanding on the available resources.

\section{Data-gathering procedure}

The in-depth interviews were captured by taking notes on the protocol forms, making an audio cassette recording of each interview and requesting a typist to transcribe each interview.

The focus group interviews were video-taped as well as audiotaped. During the interviews Benecke captured information on the field notes protocol he had designed for participant observation. Both focus group interviews were transcribed. Information on the video conference was captured on the same field notes protocol, but no audio tape or video recordings were made of this event.

Benecke also accessed documents on the Company's synergy intranet site. The nine requested essays were sent to him via e-mail.

The data were stored in six locations, namely Benecke's personal computer's hard drive; two locations on his business unit's server; a rewritable compact disc that he kept in his study; a mass storage device that he kept with his computer (most of the time); and, generally, his study at home where he kept printed hard copies, hand-written hard copies of all interviews, field notes protocols, documents such as minutes and reports and his diary as well as the audio and video cassettes.

The risk of losing information stored on the Company's server was slight, which implies that all typed information was quite safe. Material kept in Benecke's study was mainly at risk of fire and water damage, while documents kept on his personal portable computer were greatly exposed to the risk of theft and lightning.

In the study a single case was explored, seeking specific conclusions as explained by Gummesson (2000) and Collis and Hussey (2003). This was applied within the broad objectivist grounded theory paradigm as explicated by Charmaz $(2000)^{11}$. Due to the nature of the study as well as his positivistic inclinations and the size of the Company, Benecke found it difficult to terminate the fieldwork. This is not uncommon since a local researcher, Claassen (2004), indicates that qualitative researchers usually find it difficult to terminate the data collection phase. Creswell (1998) believes that categories representing units of information usually become saturated after 20 to 30 interviews. Although it cannot be claimed with certainty that all the categories in the study were saturated, themes started to recur. Taking Creswell's (1998) advice seriously, Benecke decided to terminate the fieldwork on the completion of the natural history/ research story.

\section{Ensuring quality data}

Data quality was ensured in several ways:

- The application of triangulation ${ }^{12}$ was the primary means to ensure quality data, and boiled down to the use of various data collection techniques, namely in-depth interviews, focus group interviews, follow-up essays, documents, the natural history/research story and participant observation.

- All the participants also participated voluntarily in the indepth and focus group interviews and all of them signed the informed consent form. This paved the way for using their information in the study.

- Furthermore, all the participants were assured that the information they provided would be treated confidentially and that their identities would not be disclosed.

- In addition, all the participants were asked whether they would like copies of the transcripts of their interviews. Those who were interested received copies. Only two participants indicated that they would like changes applied to the transcripts. Benecke made the changes in accordance with their wishes and destroyed the original transcripts.

- Purposive sampling was applied by selecting only employees with an "informed opinion" for the in-depth interviews (with the assistance of the Human Resource Directors) and adding data obtained from members of a study group on synergy in the Company. Two participants were selected to comment on 
Benecke's account of the participants' reality.

- Excerpts were drawn from the interviews to support the identified categories.

- Finally the natural history or internal audit trail of the study were compilled.

Data analysis

The well-known formal qualitative inferential strategy, grounded theory, was used to analyse the data. Strauss and Corbin (1998), Bogdan and Biklen (1998) and Creswell (2003) propose a coding system for analysing data within this strategy $^{13}$. Creswell (2003) points out that grounded theory has the following systematic steps: (1) generating categories of information (open coding); (2) selecting one of the categories and positioning it within a theoretical model (axial coding); and (3) creating a story from the interconnection of these categories (selective coding).

Strauss and Corbin (1998, p. 101) describe open coding as the "analytic process through which concepts are identified and their properties and dimensions are discovered in data". Benecke used the hand-written protocols (field notes) and transcripts of the in-depth and focus group interviews as main sources for open coding. The hand-written protocols and transcripts were read several times. Benecke compared field notes on each interview protocol with the transcript of that interview and used a matrix to capture themes emerging from the data per participant. This enabled him to quantify the number of times a particular theme recurred, enabling "measurement" of the strength of the theme.

According to Claassen (2004, p. 41), during open coding "the participants' voices [emerge] through excerpts of their views and stories, thus giving them a 'voice'. These verbatim quotations also serve to authenticate the identified trends and to explain my thinking and analysis patterns." Following his example, Benecke extracted excerpts from the interviews to authenticate the themes he identified. The information gleaned from the documentary sources, the natural history and the participant observation session was also used in this phase. Benecke then integrated the themes emerging from all the data sources. This resulted in 44 open codes.

Strauss and Corbin (1998, p. 123) define axial coding as the "process of relating categories to their subcategories, termed 'axial' because coding occurs around the axis of a category, linking categories at the level of properties and dimensions". During axial coding, Benecke examined the relationships between the 44 open codes and integrated them into 10 axial codes. He ensured that all the initial open codes were accommodated in the process.

Strauss and Corbin (1998, p. 143) define selective coding as the "process of integrating and refining the theory". They pose that theory development is an evolving process that occurs over a long period of time. According to them, it begins with the first bit of analysis and only ends when the research has been written up (Strauss \& Corbin, 1998). The idea is basically to develop a single storyline around which everything else is woven (Claassen, 2004)

\section{FINDINGS}

During open coding Benecke generated 44 open codes and their properties, which were systematically developed into 10 main categories (themes) with subcategories during axial coding. Table 2 contains the 10 main themes or axial codes.

During selective coding the 10 main categories were integrated into a larger theoretical scheme or central category. A central category is the main theme and sums up a pattern of behaviour (Goulding, 2002). To integrate and refine the main categories a central category needed to be formulated. This was difficult because all the "products of analysis" (Strauss \& Corbin, 1998, p. 146) had to be distilled into a few words that would explain the essence of the research. Apart from turning to the existing literature for guidance, the following criteria of Glaser (in Goulding, 2002) and Strauss and Corbin (1998) were applied to create a storyline:

- All other major categories must be linked to the central category.

- The central category must consistently recur in the data.

- The relation between the central category and the other categories must be logical.

- The phrase that describes the central category must be sufficiently abstract to allow for research in other related substantive areas.

- The central category must grow in explanatory power while it is being integrated with the other major categories.

The following storyline emerged:

The top leadership of the Company has a crucial role to play in changing the organisation's culture from one of compartmentalisation to one of synergy where the whole is more than the sum of its components. Committed leadership towards synergy is the most critical condition for changing the culture. The main tools at leadership's disposal to change the culture of the Company are reward and communication, which could be seen as prerequisites for changing the culture. In recent years the Chief Executive Officer played an important role in providing a vision for synergy initiatives in the Company.

The Company was created out of various mergers and acquisitions that took place over many years. These mergers and acquisitions led to business units that functioned independently from each other and created a legacy of compartmentalisation. Compartmentalisation was the main obstacle to achieving synergies between the business units. Other key obstacles were apathy towards synergy, self-interest of employees and the complexity of synergy as a concept, where obstacles could be seen as predictors of non-achievement of synergy.

Historically, compartmentalisation was strengthened by an unofficial policy that condoned the individualistic nature of the business units. In recent years there were various efforts to undo the compartmentalisation and remove the barriers between the business units, for example management and executive development programmes, smart partnerships and shared procurement. Potential new synergy initiatives recommended by the participants were the following: the creation of an internal marketplace where resources and information could be traded between business units; the exploitation of synergies between the sales, marketing, production and materials management departments; the exploitation of synergies between the human resource, finance and information technology departments; support for the employee exchange programme; the prioritisation of synergy initiatives; the better utilisation of the global brand image; and the exploitation of intellectual capital. Both current and potential synergy initiatives could be seen as prerequisites for achieving synergy.

The above storyline led to the central category: Leading a change process towards achieving synergy in the Company.

We believe that Benecke's conceptualisation of the social reality of synergy in the Company as experienced by the participants matches the data. It explains what was happening in the Company. We believe that the main categories delineated during axial coding are feasibly linked to the central category. 
TABLE 2:

AXIAL CODES, OPEN CODES AND EXAMPLES OF BEHAVIOUR

\begin{tabular}{|c|c|}
\hline Axial codes & Open codes \\
\hline $\begin{array}{l}\text { Theme 1: Need for } \\
\text { business units to } \\
\text { co-operate with each } \\
\text { other }\end{array}$ & $\begin{array}{l}\text { - Value of synergy for the business units. } \\
\text { - Opportunities for synergy. } \\
\text { - Importance of synergy. } \\
\text { - Global competitiveness. }\end{array}$ \\
\hline $\begin{array}{l}\text { Theme } 2 \text { : } \\
\text { Communicating for } \\
\text { synergy }\end{array}$ & $\begin{array}{l}\text { - Sharing of best practices } \\
\text { - Communication forums } \\
\text { - Communication guidelines } \\
\text { - Poor communication }\end{array}$ \\
\hline $\begin{array}{l}\text { Theme 3: Potential } \\
\text { negative impact of } \\
\text { synergy }\end{array}$ & $\begin{array}{l}\text { - Risk of synergy to the Company } \\
\text { - Destruction of unit brand value } \\
\text { - Forced co-operation } \\
\text { - Limited time for synergy drives }\end{array}$ \\
\hline $\begin{array}{l}\text { Theme } 4 \text { : Rewards for } \\
\text { synergy }\end{array}$ & $\begin{array}{l}\text { - Selling the benefits of synergy } \\
\text { - Balanced scorecard } \\
\text { - Low return on investment in synergy } \\
\text { - Recognition for synergy achievements } \\
\text { - Need for mutual benefit from synergy } \\
\text { - Global reward } \\
\text { - Value-based management } \\
\text { - Employee value creation }\end{array}$ \\
\hline
\end{tabular}

Theme 5: History of $\quad$ Policy of compartmentalisation compartmentalisation - Efforts to undo compartmentalisation

$\begin{array}{ll}\text { Theme 6: Potential } & \text { - Internal marketplace } \\ \text { new synergy } & \text { - Sales, marketing, production and materials } \\ \text { initiatives } & \text { management } \\ & \text { - Human resources, finance and information } \\ & \text { technology } \\ & \text { Employee exchange programme } \\ & \text { - Prioritisation of synergy initiatives } \\ & \cdot \text { Global brand image } \\ & \text { Exploiting intellectual capital }\end{array}$

$\begin{array}{ll}\begin{array}{l}\text { Theme 7: Current } \\ \text { synergy initiatives }\end{array} & \text { Management and executive development } \\ & \text { programmes } \\ & \text { S Synart partnerships } \\ & \text { - Procurement }\end{array}$

Theme 8: Leadership Top management must drive synergy towards synergy $\quad$ - Synergy as a long-term strategy

- Lack of commitment from senio management

$\begin{array}{ll}\text { Theme 9: Key } & \cdot \text { Current organisational structure } \\ \text { obstacles to achieving } & \cdot \text { Apathy towards synergy } \\ \text { synergy } & \cdot \text { Self-interest } \\ & \cdot \text { Complexity of synergy as concept }\end{array}$

Theme 10: Need for a • Establishing trust

change in culture $\quad$ Insecurity

- Develop a synergy culture

- Lip service

\section{Exemplary verbatim quotations}

- Divisions must work together and share customer bases.

- There is an opportunity for competitive advantage for those organisations that can leverage synergy over those that cannot. People [across the Company] do not regard synergy as very important. The Chief Executive Officer believes in it.

- On the information technology side the environment is ever changing. To be an expert in al areas is basically impossible. Because environments are becoming more complicated, there is more of a need to share knowledge to ensure that the right decisions are taken.

- Regional synergy forums pursue synergies between business units.

- Barriers between business units are breaking down

- The danger [of including synergy as a balanced scorecard item] is that employees will lose their focus on their primary objective, being the improvement of their own business unit.

- Forcing the use of the products and services of other business units will result in more problems and the benefactor getting even sloppier with service and price.

- People want to know what the benefits for them are if they do something extra. Sell benefits before you impose discipline. The bigger [the Company] gets, the bigger the opportunities for synergy. When the work is rewarding, then I shall do synergies. People are motivated by becoming part of a network. Sell them the benefits of creating successful synergies. They ask, "What will I benefit on a personal level?"

- The customer asked why don't we give him a [global organisation] card so he can use companies [of the global company] and get benefits for doing it. The card can be used for discount when you buy paint, or earn points, like Voyager miles. I think it's a huge opportunity to establish brand identity and synergies in the minds of our customers, let alone our staff. The card will work for staff too. We don't set out intending to give our staff the benefits of synergies. An annual grand prize for the best synergy initiative must be allocated.

- Previously there was a deliberate policy to force silos. Senior and middle management grew up in an environment where the policy was to encourage silos and not to worry about other departments. It is difficult to make the mind-shift from successful silos that generated promotional opportunities, to synergies

- Most of our senior executives are traders by definition. We have put synergy into a process that discourages the trading mentality. Currently we enforce a committee type of environment! Why do you not create an internal marketplace and let the guys tender, exchange services and products?

- Create forums that consist out of various business divisions that focus on the growth of market segments to devise a shared synergetic market strategy.

- Particularly on the people side we must use the skills pool. We must explore the whole concept of intellectual capital and knowledge sharing. We must look at how we can transfer employees across the globe and how we can create and share a repository of best practices. We must have something like a Rotary Exchange Programme. Many of our overseas colleagues would like to come and visit.

- So if you hear from guys who did the LDP [Leadership Development Programme] and the EDP [Executive Development Programme], you hear about synergy.

- Smart partnerships are a way to pursue synergies

- Branding of synergy is good. People are very aware of the branding. It carries a lot of weigh and we try to contribute to it. The marketing drive is a formal synergy initiative. They want all the companies in the group to do a formal marketing plan and they give us guidelines on how to do it. They force guys to think about their marketing.

- Synergy strategies must be driven from the top and must be facilitated from the top. If you try to be dogmatic, it will not work. It has to be softer.

- I'm not sure if our executives buy into synergy and drive it. The executives must have that synergy team, it must be a full-time function, across the companies. Within companies they are creating cross-functional teams and we are doing a lot now. Synergy must not be a parttime or ad hoc thing.

- The hierarchical structure of the organisation is a key problem for synergy. Business units see themselves as independent from one another and the larger organisation.

- I don't know if people are lazy or just so busy that they feel they can't afford the time or are apathetic. It's immensely frustrating for those people who do want to make it work. We as marketing team all wish we had more time to leverage it.

- I found that very few synergies come from business cases. A lot more is done through [an attitude of] "I trust you and I hope that this thing is going to work. After we've struggled, something might happen." In a business you don't have many occasions where things just happen.

- People feel threatened. Their range of knowledge and contacts give them a sense of power. Synergy can take it away.

- I said previously that synergy became a lip service type of phrase. No one is prepared to play open cards. 


\section{DISCUSSION}

Silver (in Anfara \& Mertz, 2006) defines theory as a unique way of looking at reality, an expression of someone's understanding of an aspect of nature and new and different perceptions of an aspect of the world. Bogdan and Biklen (1998) and other qualitative researchers see theory as a collection of logically related assumptions, concepts or propositions that orient thinking and research. According to Strauss and Corbin (1998, p. 22), theory "denotes a set of well developed categories (e.g., themes, concepts) that are systematically inter-related through statements of relationship to form a theoretical framework that explains some relevant social, psychological, educational, nursing, or other phenomena".

Given the above views of Bogdan and Biklen, Silver, and Strauss and Corbin on theory building, we believe a substantive theory for leading a change process towards achieving synergy in the Company was developed, because:

- We managed to reach an understanding of the social reality of synergy in the Company;

- New insight into synergy in the Company was provided

- A collection of logically related assumptions, concepts or propositions to guide future thinking and research on synergy in an organisational context was provided; and

- A set of well-developed categories (themes, concepts etc.) are offered that are systematically interrelated through stated relationships, which in turn form a theoretical framework that explains how change towards synergy may be led in the Company.

Goulding (2002) describes recontextualisation as the development of a theory so as to apply it to settings and populations other than those to which it was originally applied. Seal (1999) points out that a case study could produce theoretical principles and argues that the basis for theoretical generalisation lies in logic rather than in probability. He argues that the features present in a case study will be related to a wider population not because the case is representative but because the qualitative analysis is unassailable. Based on Goulding's and Seal's reasoning above, we believe it is reasonable to argue that the constructed theory by means of this case study may be applied to synergy-related phenomena such as mergers, acquisitions, strategic alliances, partnerships, collaboration and joint ventures.

Next we offer the theory generated by aligning the conditional/ consequential matrix (Strauss \& Corbin, 1998) with the stimulus-organism-response (S-O-R) theory (Partington, 2000). Burden (2006) demonstrates how to develop a substantive model for organisational redesign by aligning the conditional/ consequential matrix of grounded theory with the S-O-R theory. In doing so, he succeeded in creating a structured framework that could be applied by qualitative researchers who use grounded theory in organisational studies. Since the development of a systemic process-driven theoretical framework for leading change towards synergy in the Company showed some similarities with Burden's (2006) work, his framework was applied.

But what does a conditional/consequential matrix and the SO-R theory imply? Strauss and Corbin (1998, p. 181) define a conditional/consequential matrix in grounded theory as follows: "An analytic device to stimulate analysts' thinking about the relationships between macro and micro conditions/ consequences both to each other and to process."

Locke (2001) explains that a conditional matrix directs one to enquire into and specify the broad social, historical and economic conditions that may influence what one studies. Goulding (2002) describes the conditional/consequential matrix simply as a device for following the various levels of influence upon the phenomenon under study.
Partington (2000) points out that the behavioural sciences have moved towards cognitive perspectives in which the focus is on managers' conscious deliberations. These deliberations are accommodated by the S-O-R model, which sees individuals as processors of information. In management research this model focuses on the manager as mediator between environmental stimulus and behavioural response (Partington, 2000). S-O-R became popular because of the pressure to develop theories addressing the needs of managers and providing them with tools to manage change (Partington, 2000). Ligen and Klein (in Burden, 2006) also discuss how S-O-R emphasises the mediating role of the individual between environmental stimulus (cause) and behavioural response (effect).

The S-O-R theory focuses on how people's understanding of their environment leads to action. Grounded theory's interactionist origins are basically the same as that of the SO-R theory (Partington, 2000). The main concern of symbolic interactionism (on which grounded theory is based) is to understand social processes. For the symbolic interactionist, a stimulus is something that must be interpreted before a decision will be made. Similarly S-O-R theorists regard stimuli as things that must be interpreted or transformed before action will occur (Partington, 2000). Burden (2006) explains how S$\mathrm{O}-\mathrm{R}$ relates to grounded theory. Grounded theory analysts use a cause-and-effect schema to explain relationships between categories and sub-categories in much the same way their S-O-R counterparts would identify relationships between causes/ inputs and effects/outputs.

Having outlined both grounded theory and S-O-R, we now present the systemic process-driven substantive theory we constructed to facilitate change towards synergy in the Company. Partington (2000) argues that it is possible to develop an improved grounded theory framework that satisfies the requirements of the S-O-R theory by simplifying the conditional/consequential matrix and by making it more accessible to managers. He (Partington, 2000) suggests that the S-O-R theory and the conditional/consequential matrix should be aligned in order to form a new framework consisting of four broad conditions that, in turn, will influence the studied phenomenon. These conditions are: the external organisational context, the internal organisational context, managerial cognition and action.

- The external organisational context refers to external stimulus/input factors that influence synergy in the Company. Global competitiveness and profit considerations feature as external stimulus factors that influence synergy in the Company.

- The internal organisational context refers to internal stimulus/input factors that influence synergy in the Company. The internal stimulus factors are divided into stumbling blocks and enablers of synergy respectively. Both the stumbling blocks and the enablers are derived from combining first-order constructs elicited from the research participants with the abstract constructs extracted from the literature.

- Managerial cognition refers to the control management exert over synergy in the Company. Management can exert control over synergy through the balanced scorecard, ensuring that synergy benefits all role players, eliminates low return on synergy efforts, and promotes value-based management and employee value creation.

- Action refers to outputs produced by management to execute their decisions on synergy in the Company. The action of management as per the first-order and abstract constructs already discussed can be divided into communication and current and potential synergy initiatives. Action in the context of communication refers to the sharing of best practices between role players, the establishment of communication forums and the provision of communication guidelines for implementing synergy. Current synergy initiatives refer to management and executive development programmes, 
smart partnerships, procurement initiatives, and initiatives that capitalise on previous successes and avoid past pitfalls that led to failures. Potential synergy initiatives are actions required to execute decisions on the implementation of synergy in the Company. Potential synergy initiatives relate to the establishment of an internal marketplace, employee exchange programmes, the establishment of a global brand image and the exploitation of the intellectual capital of the Company.

The Figure 1 below presents the theory graphically.

\section{Contributions of the study}

We believe that the study makes a contribution, albeit modestly, to the area of leadership in performance and change at a theoretical as well as a methodological level:

- The insights into the various aspects of synergy contribute towards building a qualitative substantive theory for creating synergy.

- The application of a modernist qualitative approach and particularly grounded theory introduced qualitative methodology to synergy studies.
- The theory of leading a change process towards achieving synergy which may be used to good effect by the Company's top executives.

- Paving the way for scholars of synergy locally and elsewhere to test the application of the theory in mergers and acquisitions, strategic alliances, partnerships, joint ventures and collaboration.

- Paving the way for formulating proposals on policy regarding co-operation between the business units of the Company.

The literature on organisation synergy referred to earlier in this article points to certain limitations:

- No integrative conceptual framework of how to lead a change process towards achieving synergies in a global and diversified organisation existed. In this study an integrative conceptual framework has been created through the development of the substantive theory of synergy.

- There is no attempt in synergy studies to build conceptual frameworks of synergy in the global and diversified organisation. In this study a conceptual framework for such synergy has been built by aligning the conditional/ consequential matrix with the S-O-R theory.

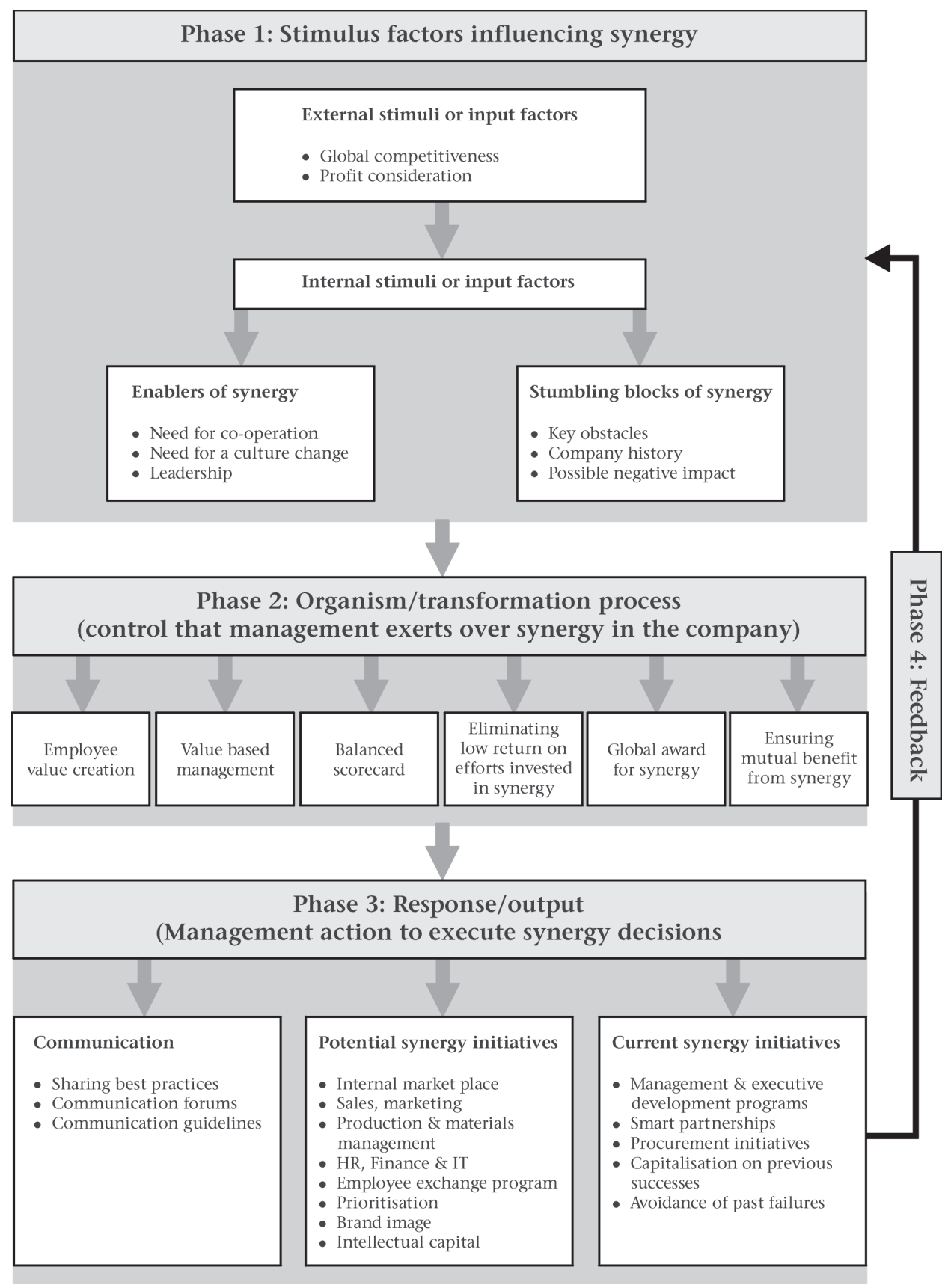

Figure 1: Substantive theory for leading a change process towards synergy 
- Research addressing resource sharing and profitability is limited (Ensign, 1998). The substantive theory developed in this study suggests specific ways of sharing resources and improving profitability.

- No synergy study that explores all synergy-relevant abstract constructs such as organisational culture, structure and change, intellectual capital, strategy, leadership, motivation, balanced scorecard, value-based management, reward and communication exists. In this study all of these abstract constructs have been addressed.

\section{Noticable limitations of the study}

While Strauss and Corbin's (1998) guidelines for grounded theory research were useful, these are, as Partington (2000) points out, rather complicated. It must be acknowledged that a somewhat mechanistic approach was used, by applying the Strauss and Corbin (1998) manuscript basically as a manual during the open, axial and selective coding.

Bogdan and Biklen (1998) recommend that qualitative researchers should not study constructs in which they are closely involved and advise them to do their research in settings to which they are strangers. They (Bogdan \& Biklen, 1998) hold that if researchers are intimately involved in a setting, it is difficult for them to distance themselves from their personal concerns. Research participants may also not relate well to someone they know. These warnings were taken to heart, and we are convinced that a sound study of the Company was undertaken because Benecke's insider position provided access to the research participants and their views of synergy that would otherwise not have been accessible.

\section{Recommendations}

We believe that in future research on synergy the following need to be considered:

- Expanding the substantive theory into formal theory.

- Explaining the relationships between the respective variables established in this study. For this purpose we strongly recommend exploring concepts related to synergy, i.e. mergers and acquisitions, strategic alliances, joint ventures, partnerships and collaboration, and the extent to which the theory developed in this study applies to them.

- Applying a quantitative approach to deductively explore the relationship between the discovered constructs further. Qualitative methods in general and grounded theory in particular are well suited to the initial discovery of constructs, whereas quantitative methods are better equipped to specify the relationships between them. This belief explains why the number of scholars who hold that both qualitative and quantitative methodologies should be used is growing (Creswell, 2003).

- Aligning the conditional/consequential matrix with the stimulus-organism-response (S-O-R) theory as suggested by Partington (2000) by Burden (2006) and in the present study.

Opportunities for applying grounded theory in the field of industrial and organisational psychology are virtually limitless. For many years this discipline has preferred quantitative methodology. As it favours a deductive approach, it can be criticised for trying to find cause-and-effect relationships between variables the researcher chooses to explore. Therefore we echo many qualitative scholars by stating that the researcher embarking upon quantitative research thus runs the risk of excluding those constructs that the research participants may regard important but which the researcher is unaware of or thinks are unimportant.

We recommend developing a research methodology whereby initial exploration of phenomena is done by means of grounded theory. Subsequent research can then deliberately be done through quantitative methods whereby relationships between variables or constructs can be further explored. By structuring (local) research in industrial and organisational psychology in this manner, we believe new light will be shed on many "old research areas/subjects", since new or previously ignored constructs and their relationships with one another will be discovered. Combining qualitative and quantitative research in this fashion provides an eclectic approach that exploits the strengths and minimises the weaknesses of the respective methodologies (Creswell, 2003).

In the preceding paragraphs we dealt exclusively with modernistic views and how these can be applied in industrial and organisational behaviour research. We believe that other qualitative applications or so-called "moments" of qualitative research also hold promise. Particularly important is autoethnography, if applied properly. This genre reflects some post-modernist developments that have brought valuable and unique insights to our study field (Ellis \& Bochner, 2000). Only selected elements of this genre were applied in the study when compiling the natural history or research story.

The present study was specifically aimed at leading change towards synergy in and between the business units of the Company. However, the Company is a dynamic entity and will certainly find itself involved in synergy-related phenomena, i.e. mergers and acquisitions, strategic alliances, joint business ventures, collaboration and partnerships. We believe that the substantive theory constructed in the study could be applied fruitfully to any of these phenomena. The Company would therefore be well advised to consider adjusting and applying the theory should any of the related phenomena occur. We believe that this theory may also be applied to similar companies elsewhere.

In conclusion we wish to state that we are convinced that this study has made a modest contribution to science by extracting constructs from the social reality of the research participants and the existing literature, which constructs are important for leading change towards synergy in the Company, one of many diversified companies in our country. As a novice lone ranger researcher in the grounded theory paradigm Benecke believes that he succeeded in creating a qualitative substantive theory that could be used to good effect by the Company to achieve synergy between its independent businesses. By subjecting this substantive construct to further well-developed and carefully executed research, we feel convinced that we can eventually develop a full-fledged or grand theory describing the relationships between its various concepts, a theory that will become an important framework for local enterprises.

\section{REFERENCES}

Anfara, V.A. \& Mertz, N.T. (2006). Theoretical frameworks in qualitative research. Thousand Oaks: Sage.

Argenti, P.A. (1994). The portable MBA desk reference, an essential business companion. New York: John Wiley.

Benecke, G. (2006). Synergy in a globally diversified organisation. Unpublished D Com thesis. Promoter: Prof W Schurink and co-promoter Prof G Roodt. Johannesburg: University of Johannesburg.

Bogdan, R.C. \& Biklen, S.K. (1998). Qualitative research for education: An introduction to theory and methods. Boston: Allyn and Bacon.

Burden, F.J. (2006). The development of an organizational redesign model: A South African case study. Unpublished doctoral dissertation, University of Johannesburg.

Chang, Y.M. (1990). Synergy, relatedness, and organization form in the strategic management of diversification. Unpublished doctoral dissertation, University of Illinois at UrbanaChampaign.

Charmaz, K. (2000). Grounded theory: Objectivist and constructivist methods. In: N.K. Denzin \& Y.S. Lincoln (Eds), Handbook of Qualitative Research, pp. 509-535. London: Sage. 
Claassen, G. (2004). Male menopause and decision-making: A qualitative study. Unpublished doctoral dissertation, Rand Afrikaans University, Johannesburg.

Cockerill, S.K. (1995). Unfolding systemic ideas. Executive Development, 8(4), pp. 4-8.

Collis, J. \& Hussey, R. (2003). Business research: A practical guide for undergraduate and postgraduate students ( $2^{\text {nd }}$ ed.). New York: Palgrave MacMillan.

Creswell, J.W. (1998). Qualitative enquiry and research design: Choosing among five traditions. Thousand Oaks: Sage.

Creswell, J.W. (2003). Research design: Qualitative, quantitative and mixed methods approaches ( $2^{\text {nd }}$ ed.). Thousand Oaks: Sage.

Denzin, N.K. \& Lincoln, Y.S. (Eds.) (2000). Handbook of qualitative research ( $2^{\text {nd }}$ ed.). Thousand Oaks: Sage.

Dey, I. (1993). Qualitative data analysis. New York: Routledge

Ellis, C. \& Bochner, A.P. (2000). Autoethnography, personal narrative, reflexitivity. In: N.K. Denzin \& Y.S. Lincoln (Eds) Handbook of Qualitative Research (2 ${ }^{\text {nd }}$ ed., pp. 733-768). Thousand Oaks: Sage.

Ensign, P.C. (1998). Interrelationships and horizontal strategy to achieve synergy and competitive advantage in the diversified firm. Management Decision, 36(10), pp. 657-668.

Franzsen, D., Van der Merwe, R., Buys, S., Bischoff, A. Courtney, F., Varachia, A., Cox, E. \& Miller, C. (2001). Synergies in the distribution business of Barloworld. Unpublished manuscript, Barloworld Leadership Development Programme, Gordon Institute of Business Science, Johannesburg.

Gill, J. \& Johnson, P. (2002). Research methods for managers ( ${ }^{\text {rd }}$ ed.). London: Sage.

Glaser, B.G. \& Strauss, A.L. (1967). The discovery of grounded theory: Strategies for qualitative research. Chicago: Aldine.

Goulding, C. (2002). Grounded theory: A practical guide for management, business, and market researchers. London: Sage.

Gummesson, E. (2000). Qualitative methods in management research ( $2^{\text {nd }}$ ed.). London: Sage.

Gupta, O. \& Roos, G. (2001). Mergers and acquisitions through an intellectual capital perspective. Journal of Intellectual Capital, 2(3), pp. 297-309.

Harris, P.H. (2004). European leadership in cultural synergy. European Business Review, 16(4), pp. 358-380.

Harwood, C.J. (2000). Review of "Synergy matters: Working with systems in the twenty-first century" by A.M. Castell, A.J. Gregory, G.A. Hindle, M.E. James and G. Ragsdall (Eds), Kybernetes, 29(4), pp. 523-529.

Hergenhahn, B.R. (1976). An introduction to theories of learning. New Jersey: Prentice-Hall.

Juga, J. (1996). Organising for network synergy in logistics. International Journal of Physical Distribution and Logistics Management, 26(2), pp. 51-67.

Krumm, J.M.M., Dewulf, G. \& De Jonge, H. (1998). Managing key resources and capabilities: pinpointing the added value of corporate real estate management. Facilities, 16(12/13), pp. 372-379.

Locke, K. (2001). Grounded theory in management research. London: Sage.

Mason, J. (1996). Qualitative researching. London: Sage.

Mouton, J. (1985). Contemporary philosophies of science and the qualitative paradigm in the social sciences. South African Journal of Sociology, 16(3), pp. 81-89.

Mouton, J. \& Marais, H.C. (1990). Basic concepts in the methodology of the social sciences (rev. ed.). Pretoria: HSRC Printers.

Naudé, A., Heyns, D., Bester, C., Puig, J. \& Tucker, G. (2002). Synergies within Barloworld. Unpublished manuscript, Barloworld Executive Development Programme, Gordon Institute of Business Science, Johannesburg.

Paich, M.R. (1996). Budget fusion: a profitable synergy of systems and people investment. Industrial and Commercial Training, 28(1), pp. 26-28.

Parentau, R.S. \& Weston, J.F. (2003). It's never too early to think integration. Mergers and Acquisitions, 38(11), pp. 17-23.

Partington, D. (2000). Building grounded theories of management action. British Journal of Management, 11, pp. 91-102.

Pun, K.F. (2004). A conceptual synergy model for strategy formulation for manufacturing. International Journal of Operations and Production Management, 24(9), pp. 903928.

Rowley, J. (2002). Synergy and strategy in e-business. Marketing Intelligence and Planning, 20(4), pp. 215-222.

Schurink, W.J. (2004, 27-28 February). Qualitative research: Introducing key features of an interpretive approach to social science research. Paper presented at the second study school for Rand Afrikaans University post-graduate students in the Leadership in Performance and Change Programme, Johannesburg.

Seale, S. (1999). The quality of qualitative research. London: Sage.

Shaver, J.M. (2006). A paradox of synergy: contagion and capacity effects in mergers and acquisitions. Academy of Management Review, 31(4), 962-976.

Steinfield, C., De Wit, D., Adelaar, J., Bruins, A., Fielt, E., Hoefsloot, M., Smit, A. \& Bouwman, H. (2001). Pillars of virtual enterprise: Leveraging physical assets in the new economy. The Journal of Policy, Regulation and Strategy for Telecommunications, Information and Media, 3(3), pp. 203-213.

Strauss, A. \& Corbin, J. (1998). Basics of qualitative research: Techniques and procedures for developing grounded theory ( $2^{\text {nd }}$ ed.). Thousand Oaks: Sage.

Strydom, H. \& Delport, C.S.L. (2002). Sampling and pilot study in qualitative research. In: A.S. de Vos, H. Strydom, C.B. Fouché and C.S.L. Delport (Eds), Research at grass roots, pp. 333-338. Pretoria: Van Schaik.

Waco, M. \& Wery, R. (2004, January). How to integrate international acquisitions to realize lasting synergies. World Trade, 48-51. 